\section{Para além da compra de votos: como os eleitores moldam e sustentam as relaçóes clientelistas no Brasil}

\section{Beyond vote buying: how voters shape and sustain clientelist relationships in Brazil}

NICHTER, Simeon. (2018), Votes for survival. Relational Clientelism in Latin America, Cambridge, University Press.

\section{Marta Mendes da Rocha (1) \\ https://orcid.org/0000-0003-0857-6488}

(1) Professora do Departamento de Ciências Sociais e do Programa de Pós-graduação em Ciências Sociais da Universidade Federal de Juiz de Fora, Minas Gerais, MG, Brasil.E-mail: mendes_rocha@yahoo.com.br

DOI: $10.1590 / 3510418 / 20$

Ao lado de outros "ismos", o clientelismo sempre ocupou um lugar privilegiado nos estudos sobre a política no Brasil, seja na tradição do pensamento político e social brasileiro, seja em estudos mais recentes nas três áreas das Ciências Sociais. Ainda que mobilizado de forma bastante vaga e imprecisa, o clientelismo se afirmou, no imaginário acadêmico, como traço marcante da política brasileira, quase sempre associado a uma série de males e fragilidades de nossa democracia.

Ainda assim, de uns tempos para cá, havia razóes para crer que o clientelismo -entendido como uma relação de troca entre políticos, que fornecem benefícios de forma particularizada, e eleitores, que retribuem com seu apoio político e voto - teria cedido espaço para outras formas de exercício da representação e de intermediaçáo de interesses. Boa parte dos estudos clássicos sobre o tema, nos anos 1960 e 1970, em consonância com os postulados das teorias da modernização, argumentam que o desenvolvimento econômico, a redução da pobreza, o avanço da urbanizaçáo e a ampliaçáo dos níveis de escolarização, somados à emergência de uma política competitiva, tenderiam a minar as relaçóes clientelistas, enfraquecer as máquinas políticas e criar incentivos para que políticos, partidos e eleitores passassem a se comportar em termos de uma política programática e ideológica. Nas duas décadas seguintes, outros estudos, a partir de uma abordagem institucional, destacaram o efeito negativo de reformas eleitorais - como a introdução do voto secreto e da legislação para coibir a compra de votos - sobre o clientelismo (Kitschelt e Wilkinson, 2007).

O debate sobre este conjunto de estudos constitui o ponto de partida da argumentação de Simeon Nichter, em Votes for Survival: relational clientelism in Latin America. Apesar do título mais abrangente, trata-se de um livro sobre o clientelismo no Brasil que, como pretendo demonstrar, deve vir a ocupar um lugar de relevo na nova onda de estudos sobre o tema.

O problema de pesquisa de Nichter é: se o Brasil passou por todas as transformaçóes supracitadas dentre as quais destacam-se o desenvolvimento econômico, a redução da pobreza, e as reformas institucionais voltadas ao fortalecimento da integridade do processo eleitoral e geralmente associadas a uma dinâmica política de caráter mais programático, por que o clientelismo ainda se mostra surpreendentemente disseminado no país? Com foco na política municipal, o autor busca explicar, ao longo de oito capítulos agrupados em três partes, os fatores que contribuem para a manutenção das relaçôes clientelistas no país, bem como os mecanismos que garantem a credibilidade das promessas feitas de parte a parte, por eleitores e políticos. Além disso, em um dos capítulos do livro, o autor analisa a aplicação de seu principal argumento em outros países da América Latina e de outras partes do mundo.

O livro de Nichter se soma a um conjunto de pesquisas que vêm conformando uma nova onda de estudos sobre o clientelismo. De fato, este tema vem sendo objeto de um revival na literatura internacional, com a multiplicação de investigaçôes que, em pelo menos dois aspectos, diferenciam-se dos estudos desenvolvidos nos anos 1950 e $1970 .{ }^{1}$ Em primeiro lugar, essa nova leva de pesquisas tem se empenhado em definir de forma mais precisa o clientelismo, de modo a distingui-lo de outras formas de intermediação de interesses e, também, oferecer uma base mais segura 
para a sua mensuração. $\mathrm{O}$ segundo aspecto distintivo desta nova produção reside na forte orientação empírica dos estudos, marca igualmente presente nos atuais esforços de compreensão do clientelismo no Brasil, incluindo o trabalho de Nichter.

Em conjunto, estas pesquisas vêm contribuindo para lançar luzes sobre uma variedade de aspectos e problemas relacionados ao clientelismo, destacando-se os fatores - individuais, organizacionais, institucionais e contextuais - que predispóem eleitores e políticos a se empenharem neste tipo de troca e seus respectivos impactos políticos e socioeconômicos; o papel dos operadores políticos; e os mecanismos de monitoramento empregados de lado a lado. Contudo, apesar dos avanços mencionados, tanto a literatura internacional, como as pesquisas realizadas por brasileiros e/ou sobre o Brasil continuam padecendo de problemas que, tradicionalmente, marcam os estudos sobre o tema. É neste sentido, portanto, que, conforme busco argumentar, Nichter oferece contribuiçôes significativas para superar algumas das deficiências apontadas.

Antes de destacar as principais contribuiçóes do livro e, ao mesmo tempo, ressaltar algumas de suas lacunas, é importante sublinhar um dos aspectos que mais salta aos olhos nessa obra. Impressiona a variedade de técnicas de pesquisa utilizadas e o enorme volume de dados e evidências quantitativas e qualitativas, mobilizadas em suporte ao argumento central. Além de dados disponibilizados por outras instituições e projetos de investigação, o autor conduziu dois surveys originais com eleitores, sendo um deles realizado em mais de mil municípios brasileiros. A pesquisa contemplou, ainda, dezoito meses de imersão e trabalho de campo no Nordeste do país, durante os quais foram realizadas entrevistas formais com eleitores e membros da elite local.

Mobilizando um amplo e variado conjunto de estratégias, fontes e dados, Nichter busca demonstrar que os eleitores desempenham um papel indispensável na manutenção do clientelismo, sendo a vulnerabilidade um fator central para predispor os cidadáos às trocas clientelistas. Neste sentido, o autor destaca a importância de dois mecanismos que visam dotar de credibilidade as promessas feitas de parte a parte: a apresentação de pedidos aos políticos e a declaração pública de apoio a eles.

Ao declararem apoio - por meio de exibição de material de campanha em domicílios, veículos e vestimentas -, os eleitores fornecem informação e sinalizam aos políticos a consistência de seu compromisso. Ao apresentarem seus pedidos, eles avaliam a credibilidade dos políticos e realizam uma espécie de triagem entre aqueles que merecem, ou não, a sua confiança, como eleitor. Os pedidos atendidos possibilitam que os políticos desenvolvam uma reputação de confiabilidade e, dessa forma, de lado a lado ambos contribuem para a sustentabilidade dos acordos. Trata-se de um argumento original, já que, até então, boa parte da literatura tendia a prestar atenção em outras formas de monitoramento, por exemplo, por meio dos operadores políticos (brokers).

Com esse argumento, Nichter oferece uma explicação original para uma questão que intriga os estudiosos da política distributiva: o fato de os eleitores já inclinados a votar nos partidos e nos políticos os chamados core voters -, e não os indecisos (swing voters), aparecerem como os principais focalizados para a distribuição de benefícios particulares (Cox e McCubbins, 1986; Stokes et al., 2013). Tal comportamento - que, para alguns estudiosos, parecia uma estratégia subótima dos políticos - recebe, em Votes for Survival, outra interpretação. Nichter entende que os eleitores leais recebem mais benefícios, não porque são focalizados, mas sim porque os demandam. Boa parte dos recursos distribuídos seriam, portanto, respostas aos pedidos dos eleitores. A originalidade do argumento de Nichter está em interpretar aquilo que boa parte da literatura vê como estratégias de políticos e partidos para maximizar votos (ou comparecimento de simpatizantes, turnout buying), como políticos atendendo a pedidos dos eleitores prática que ocorreria durante e também depois do período eleitoral, de forma sustentada no tempo. Tal interpretação só é possível pelo fato de Nichter tirar o foco dos políticos e colocá-lo nos eleitores.

Combinando evidências quantitativas e qualitativas, o autor mostra que a declaração pública de apoio é uma prática corrente entre os eleitores brasileiros, e que há uma crença disseminada entre eles, de que a declaração de apoio impacta a probabilidade de 
tornarem-se alvo de benefícios. Os dados dos surveys originais revelam que, de fato, aqueles que declararam apoio a um prefeito vencedor apresentaram maior probabilidade de serem alvo de um benefício particular no ano seguinte à eleição, comparativamente aos eleitores que náo declararam apoio. As conclusóes se mantêm, quando Nichter, empregando técnicas de análise de regressão, inclui controles por meio das características socioeconômicas e políticas dos entrevistados. $\mathrm{O}$ mesmo pode ser dito a respeito da apresentação de pedidos, uma vez que a maior parte dos eleitores que recebeu um benefício particular havia feito tal solicitação, geralmente motivada pela vulnerabilidade, e apresentou mais chances de ser atendida comparativamente aos que náo o solicitaram. Um dos méritos do desenho desta pesquisa é o fato de ela permitir apreender a dimensão da condicionalidade na distribuição dos benefícios, uma dificuldade recorrente nos estudos sobre o tema. No capítulo comparativo, Nichter mostra evidências de vínculo entre, de um lado, apresentar pedidos e declarar apoio, e, de outro lado, a experiência com o clientelismo, em outros países. Entretanto, com a limitaçẫo de dados disponíveis acerca dos demais países, as evidências são apenas sugestivas.

Pelo menos em três aspectos, Nichter oferece uma contribuição de peso aos estudos sobre clientelismo. $\mathrm{O}$ primeiro deles remete à distinçăo entre clientelismo eleitoral e relacional. Trata-se de uma diferenciação já enunciada em trabalhos anteriores do próprio autor (Nichter, 2010), e que permite superar um problema patente nos estudos sobre o tema, uma vez que boa parte da literatura trata clientelismo e compra de votos como sinônimos. Alguns autores propóem que a compra de votos seria um subtipo de clientelismo (Stokes et al., 2013); e mesmo os que admitem a necessidade de distinguir as trocas em funçáo de sua temporalidade, acabam por misturá-las, no momento de operacionalizar o conceito. Por sua vez, os cross-national surveys mais mobilizados pelos pesquisadores, como o AmericasBarometer (LAPOP), por exemplo, focalizam o período eleitoral. Portanto, o primeiro aspecto louvável do trabalho desenvolvido por Nichter consiste no esforço em estabelecer uma distinção entre as trocas que ocorrem no período eleitoral e as que extrapolam as campanhas, atentando para a dimensão da temporalidade.
O clientelismo eleitoral, que se caracterizaria por trocas mais episódicas, concentradas no período de campanha, quando os eleitores recebem os benefícios antes de votar, é abordado no capítulo 2. Segundo Nichter, este tipo, que seria menos passível de deserção, persiste no Brasil, ainda que mitigado, como sugerem diversas pesquisas. O clientelismo relacional, foco do livro, como o próprio título indica, é abordado a partir do capítulo 3, e definido como "ongoing exchange relationships that extend beyond election campaigns" ("relaçôes de troca contínuas que extrapolam as campanhas eleitorais" - tradução nossa) $(2018$, p. 5). Este tipo de clientelismo seria mais resiliente e menos afetado pelas reformas institucionais e pelas medidas legais destinadas a combater a compra de votos. Segundo Nichter, é especificamente quanto às trocas que extrapolam o período eleitoral, que se pode dizer que o clientelismo se mantém surpreendentemente forte e disseminado no país.

Outra inovação importante do livro é o foco colocado no eleitor (demand side), e náo nas elites políticas (supply side). Nichter argumenta que, entre os estudiosos, há uma tendência em reservar aos eleitores um papel passivo nas trocas e superestimar a importância dos políticos. De fato, a literatura tende a atribuir aos políticos a decisão de quem receberá o quê, como e quando. Eles seriam os responsáveis por definir a economia das trocas. Nichter propóe inverter essa lógica, focalizando nas açôes dos eleitores e no modo como elas contribuem para a manutenção do clientelismo. Para o autor, depositar atenção no papel desempenhado pelos eleitores torna-se especialmente importante, no contexto de um clientelismo competitivo e de um eleitor mais autônomo, que conta com garantias básicas (o voto secreto seria uma delas) e opçóes de saída da relação.

Como o clientelismo se define por uma relação, é quase um truísmo afirmar que devemos prestar atençấo aos dois lados. Nenhuma compreensão sobre a prática será possível, sem incorporar os perfis, as condiçōes e as motivações de ambas as partes. A contribuição do livro está, justamente, em descortinar um conjunto de aspectos relativos ao ponto de vista da demanda, não apenas pela qualidade e consistência das evidências, mas por propor uma outra chave de interpretaçâao para o clientelismo. Contudo, considero problemático o fato de que, por vezes, os políticos 
sejam apresentados quase como reféns dos eleitores, premidos pela necessidade de atender a pedidos particulares, já que é isso que os eleitores esperam deles e que é crucial para a sua sobrevivência política. O velho dilema se apresenta: são os políticos que se engajam nas trocas clientelistas, respondendo a um conjunto de expectativas compartilhadas pelos eleitores, ou são os eleitores que se engajam nas trocas, já que os políticos as priorizam e as recompensam? O livro não pretende responder a esta questão, mas as conclusões nele apresentadas recolocam a importância do problema.

Uma terceira e importante contribuição do estudo está na forma como o autor articula a dimensão da pobreza e suas conexóes com o clientelismo. Um dos fatos mais estabelecidos na literatura sobre o clientelismo é o de que ele é mais disseminado nos países pobres e entre os pobres. Contudo, a despeito das várias evidências que embasam a associação entre clientelismo e pobreza, esta variável tem sido mobilizada de forma pouco sistemática em boa parte dos trabalhos sobre o tema. Por se tratar de um aspecto tão central nas abordagens sobre o clientelismo, é imperativo que os estudiosos se empenhem em um tratamento mais detido sobre a dimensão da pobreza. O que se quer exatamente designar, quando se fala em pobreza? Qual é a melhor forma de operacionalizar o conceito? A pobreza deveria sempre ser mensurada única ou principalmente a partir da renda? Se esta for a dimensão central do conceito, qual é o limiar de renda abaixo do qual aumentam as chances de os eleitores trocarem seus votos por benefícios particulares?

Em sua pesquisa, Nichter dedica mais atenção ao problema da relaçáo entre pobreza e clientelismo, do que se verifica usualmente na literatura. A vulnerabilidade passa a ser a categoria central operacionalizada a partir de duas variáveis: a pobreza, indicada pela renda, e o risco, indicado pela insegurança em relação à capacidade de suprir necessidades básicas. Especificamente, ele considera três fontes de insegurança: acesso a serviços de saúde, emprego e suprimento de água. A vulnerabilidade é vista, assim, como resultado de falhas do Estado em prover um adequado sistema de proteção social e do fato de que os políticos locais possuem os recursos e a discricionaridade necessários para preencher as lacunas deixadas pelo sistema. $\mathrm{O}$ autor mostra que, a despeito da redução da pobreza no país, muitos brasileiros continuam ameaçados pelo risco de não serem capazes de suprirem suas necessidades básicas e sujeitos a outras fontes de insegurança, possibilitando entender a persistência do clientelismo.

No capítulo 4, Nichter apresenta evidências de que a vulnerabilidade constitui uma forte motivação para que os eleitores apresentem pedidos e declarem apoio aos políticos, na esperança de serem recompensados com benefícios associados às três fontes de insegurança acima apontadas.

Tendo destacado, em minha avaliação, as principais contribuiçóes do livro, devo agora me ater ao que considero suas principais lacunas e problemas. Um primeiro aspecto que merece ser dito é o de que, apesar das inúmeras e consistentes evidências apresentadas por Nichter, de que o clientelismo permanece bastante difundido no país, especialmente entre a população mais vulnerável, este não é um aspecto de todo incontroverso. Outros autores, em estudos recentes, mostram evidências em sentido contrário. É o caso de Souza (2015), que tomando a Bahia como estudo de caso - o mesmo estado privilegiado por Nichter, em sua análise -, apresenta indícios de deslocamento de uma política de tipo marcadamente clientelista, para uma de tipo mais programático, como resultado da implementação de políticas de combate à pobreza. Segundo Souza, o Programa Bolsa Família poderia ser considerado "um golpe contra as práticas clientelistas do passado que caracterizaram as políticas sociais implementadas pelos diversos níveis de governo" (p. 349, tradução nossa). Outras políticas semelhantes teriam o mesmo efeito de "quebrar a interdependência entre os eleitores pobres e os políticos” (p. 349, traduçâo nossa)” (p. 349).

Perspectiva semelhante encontramos em Borges (2007), que argumenta que certas características da política brasileira - competição vertical na provisão de serviços públicos, entre atores políticos localizados em diferentes esferas de governo; aumento da competitividade eleitoral; e fragmentação partidária - funcionam como constragimentos à construção de redes clientelistas estáveis. Embora o foco do autor esteja no processo político estadual, suas conclusóes recomendam maior ceticismo quanto à capacidade de as elites locais controlarem a arena política ao longo do tempo. $\mathrm{O}$ argumento de Borges não deve ser visto 
como diamentralmente oposto ao de Nichter, que reconhece a natureza competitiva do clientelismo no Brasil contemporâneo. Porém, o quadro oferecido por Borges difere, na medida em que, para ele, "o poder das máquinas políticas estaduais repousa em fundações frágeis" (2007, p. 108, tradução nossa), inclusive naqueles estados tidos como bastiôes de oligarquias políticas.

Por fim, há que se considerar que a própria categoria "clientelismo" é contestada, em termos de sua capacidade para prover um quadro interpretativo e explicativo satisfatório para os processos políticos na Nova República. Usado, em geral, de forma vaga e imprecisa, para caracterizar ou desqualificar políticos, políticas e partidos, o conceito é não raro empregado como categoria de acusaçáo contra adversários políticos, para embasar, fragilmente, diagnósticos sobre a desfuncionalidade das instituiçóes brasileiras ou, então, como forma de negação da política.

As referências supracitadas mostram o caráter ainda controverso da questáo referente aos impactos das mudanças sociodemográficas, econômicas e políticoinstitucionais ocorridas no país, nas últimas décadas. Portanto, parece existir mais questóes em aberto, do que Nichter sugere na conclusão do livro. Não fica de todo claro, por exemplo, se e em que medida suas consideraçóes finais podem ser generalizadas para os municípios mais populosos do país, com economias mais diversificadas, uma dinâmica eleitoral bastante competitiva e o predomínio de relaçóes mais impessoais.

Além disso, o autor náo explora a fundo o papel dos partidos políticos, neste processo. Ainda que a análise mostre que a preferência do eleitor por este ou aquele partido não impacta as chances de ele vir a experimentar o clientelismo, disso não decorre que políticos de diferentes partidos estejam, indistintamente, predispostos à prática. Estudos sobre elites políticas sugerem que os diferentes padróes de carreira e trajetórias, nos partidos de esquerda e de direita, geram diferentes disposiçóes e atitudes em relação ao clientelismo.

Outra questáo que permanece em aberto e que, para o argumento central do texto, mostra-se particularmente importante, diz respeito à forma de interpretar a declaração pública de apoio a um político ou candidato. Nichter admite que existem diferentes motivaçóes para declarar apoio, e que tal ação não deve ser sempre considerada como sendo orientada por interesses puramente materiais. Por que não interpretar a declaração de apoio como ativismo político? Como distinguir as duas coisas? As duas motivaçóes não poderiam coexistir?

Por último, mas não menos importante, destaco o que considero ser a principal lacuna do livro, que remete ao silêncio quase completo do autor em relação ao papel dos operadores políticos, ou brokers. Nichter não reserva nenhum espaço de relevo para estes atores, em sua explicação sobre os mecanismos que impulsionam e sustentam o clientelismo. Também não ficam claras as razóes pelas quais eles são ignorados. Parte-se da premissa de que, nos municípios pequenos e médios, que recebem especial atenção na investigação, os brokers são menos importantes devido à possibilidade de manutenção de relações face a face? A apresentação de pedidos e a declaração de apoio pelos eleitores dispensariam os brokers, em seu papel de prover informação e monitorar o comportamento das partes?

Vários estudos enfatizam a importância destes atores para a manutenção das relaçóes clientelistas. Stokes et al. (2013), em trabalho recente, chegam a propor que a compreensão do papel desempenhado pelos mediadores é a chave para entender por que o clientelismo prospera e em quais condiçóes ele enfraquece. A importância atribuída pela literatura (Auyero, 2001; Levitsky, 2003; Stokes et al. 2013; Zarazaga, 2014; Holland e Palmer-Rubin, 2015)² aos operadores políticos contrasta com a sua quase ausência em Votes for Survival. No que se refere aos dois mecanismos centrais na explicação de Nichter, algumas questões que persistem são: Como os pedidos são feitos? Diretamente aos prefeitos e autoridades locais? Por meio de intermediários? Quem faz a intermediação? Os vereadores? Estes seriam, acima de tudo, brokers do prefeito, dadas as suas limitações em eles mesmos atenderem aos pedidos dos eleitores? Enfim, predominam relaçóes diretas ou mediadas?

É difícil crer que os políticos sejam capazes de observar diretamente o comportamento de cada eleitor, de modo a definir quem deve, ou não, ser recompensado. Se as evidências apresentadas pelo autor explicitam a importância dos eleitores, em dotar de credibilidade as promessas e sustentar as relaçóes de troca, elas náo permitem, por sua vez, destacar 
que outros mecanismos de controle - o emprego de mediadores, por exemplo - sejam igualmente ou ainda mais importantes.

A despeito das objeçôes apontadas, não resta dúvida de que Votes for Survival se converterá em uma referência obrigatória para os estudiosos do clientelismo, no Brasil e em outras partes do mundo. As qualidades e méritos do trabalho, que em muito superam suas deficiências, refletem um empreendimento de pesquisa ambicioso e original, com importantes e valiosas liçóes para pesquisadores do comportamento político.

\section{Notas}

1 Segundo Stokes (2007), a primeira geração de estudos sobre clientelismo remete ao pós-Segunda Guerra Mundial, período no qual prevaleceram as abordagens da sociologia e da antropologia, com estudos de caso de caráter qualitativo. A segunda geração remonta aos anos 1970 e 1980 e diferencia-se da primeira, pela investigaçáo do clientelismo no contexto de democracias competitivas, indo além das abordagens desenvolvimentistas, e levando mais a sério os processos de formação do Estado e as instituiçôes, como eleiçôes, partidos políticos e burocracias públicas.

2 Especificamente para o caso brasileiro, ver Novaes, 2015.

\section{REFER $\hat{E N C I A S}$}

AUYERO, Javier. (2001), Poor people's politics: peronist survival networks and the legacy of Evita, Durham, Duke University Press.
BORGES, André. (2007), "Rethinking State Politics: The Withering of State Dominant Machines in Brazil”. Brazilian Political Science Review, 2: 108-36.

COX, Gary W. e McCubbins, Mathew D. (1986), "Electoral politics as a redistributive game". Journal of Politics, 48, 2: 370-389.

HOLLAND, Alisha C. e PALMER-RUBIN, Brian. (2015), "Beyond the Machine Clientelist Brokers and Interest Organizations in Latin America". Comparative Political Studies, 48, 9: 1186-1223.

KITSCHELT, Herbert e WILKINSON, Steven. (eds.). (2007), "Citizen-politician linkages: an introduction". Patrons, Clients, and Policies: Patterns of Democratic Accountability and Political Competition, Cambridge, Cambridge Univ. Press.

LEVITSKY, Steve. (2003), Transforming Labor-based parties in Latin America: Argentine Peronism in Comparative Perspective, Cambridge, Cambridge University Press.

NICHTER, Simeon. (2010), Politics and Poverty: Electoral Clientelism in Latin America. Tese de Doutorado, Departamento de Ciência Política, Berkeley, Universidade da California.

NOVAES, Lucas M. (2015), "Disloyal Political Brokers and the Problem of Clientelistic Party Building". Mimeo. Disponível em: https://ebape.fgv.br/sites/ebape.fgv.br/ files/promiscPoliticians+1.pdf, consultado em 29/01/2020.

SOUZA, Celina. (2015), "Breaking the Boundary: Pro-Poor Policies and Electoral Outcomes in Brazilian Sub-National Governments". Regional \& Federal Studies, 25, 4: 347-63.

STOKES, Susan (2007), "Political clientelism", in C. Boix e S. C. Stokes (eds.), Oxford Handbook of Comparative Politics, Nova York, Oxford University Press, 604-627.

STOKES, Susan; DUNNING, Thad; NAZARENO, Marcelo; BRUSCO, Valeria. (orgs.). (2013), Brokers, voters and clientelism: the puzzle of distributive politics, Nova York, Cambridge University Press.

ZARAZAGA, Rodrigo. (2014), "Brokers beyond clientelism: A new perspective on brokerage through the Argentine case". Latin American Politics and Society, 56, 3: 23-45. 